\title{
A Review on Image Analysis Approaches for Estimating Chlorophyll Content from Leaf Images
}

\author{
Mamatha V. \\ Dept. of Computer Science \\ College of Engineering Poonjar
}

\author{
Sreekumar K. \\ Dept. of Computer Science \\ College of Engineering Poonjar
}

\begin{abstract}
The green, or the chlorophyll- bearing, plants are the only living forms on this planet capable of fusion of organic matter out of inorganic elements and simple compounds. Automatic identification of plant leaf is a demanding problem in the area of computer vision. Plant chlorophyll estimation can support nitrogen fertilization decisions. Chlorophyll content is a key measure of plant growth and physiological status.
\end{abstract}

Chlorophyll (green colour) is the most notable tetrapyrrol, while the most important tetraterpenoids and carotenoids (yellow-orange-red colour). Chlorophyll was first identified and named by Joseph Bienaimé Caventou

and Pierre Joseph Pelletier in 1817 -The existence of magnesium in chlorophyll was discovered in 1906, and was the first time that magnesium had been detected in living tissue.

\section{Keywords}

chlorophyll estimation, plant leaf analysis, image analysis, plant vigor estimation.

\section{INTRODUCTION}

Plants are important to other life on this planet because they form the basis of all food webs. Most plants are autotrophic ,generating their own food using water ,carbon dioxide and a light through a process called photosynthesis. Some of the untimely fossils found have been aged at 3.8 billion years. In earlier times anything that was green and that wasn't an animal was considered as a plant. Chlorophyll consists of several related green pigments found in plants. Chlorophyll is important in photosynthesis, allowing plants to absorb energy from light .Plants have mainly chlorophyll a and chlorophyll b. Image processing is a method used for plant nitrogen and chlorophyll identification. The leaf chlorophyll contend is determined to detect the vegetation productivity by recognizing the physiological stress and managing biological resources.

Researchers are using different techniques for estimation. Some researchers are using light sensors, while others use Minolta SPAD-502 plus chlorometer. Many studies in the earlier cases have shown that leaf contains rich information like color, shape etc .In order to estimate the chlorophyll content, we need to identify the leaf colour and the spectral vegetation indices.The leaf reflectance data are collected using ASD fieldspec Pro spectroradiometer.

The canopy reflectance data are obtained from MERIS(medium resolution imaging spectrometer).The main feature is leaf area index. The nutrient deficiency can be identified by using JIP test parameters. They are used for analyzing deficient condition. Some of the classifiers like ANN, SVM are used.

Chlorophyll are pervasive pigments in the plant kingdom that play a key role in photosynthesis. Many steps are used for the chlorophyll evaluation. In order to recognize the chlorophyll content, we need to discriminate under some features like light, colour and pigments. . The visible spectrum of light includes the colors of the rainbow ( Red, Orange, Yellow, Green, Blue, Indigo, and Violet). Different plants have different quantity of green pigmentation.

Chlorophylls consume light most strongly in the blue portion of the electromagnetic spectrum as well as the red portion Chlorophyll. There are five types of chlorophyll :chlorophyll a is present in all photosynthetic organisms except bacteria; chlorophyll $\mathrm{b}$, in plants and green algae; and chlorophylls $\mathrm{c}, \mathrm{d}$ and $\mathrm{e}$, in some algae.

\section{A REVIEW THROUGH LITERATURE}

Botany is the systematic study of plants and plant-like organisms. It helps us to understand why plants are so mandatory important to the world. Plants start the majority of food and energy chains, they supply oxygen, food and medicine. Plant taxonomy is a study of plants that helps us to understand about the plant groups. Plants play a vital role in human life. We need to estimate the chlorophyll contend in the leaves, by using various measures.

The features like colour, size,etc. .are to be determined for the estimation purpose.The health of the plant mainly depends on the chlorophyll contend in it. It is an important feature in photosynthesis. Using digital cameras, we can identify the colour pigmentations in the leaves.

We use Minolta SPAD-502 TM to estimate the cholorophyll contend in the leaves. In the latest inventions, they estimate the leaf area index and leaf chlorophyll contend using multi angle spectral data. In the paper named "Improved estimation of leaf area index and leaf chlorophyll content of a potato crop using multi-angle spectral data - potential of unmanned aerial vehicle imagery" [1],by peter.J.Roosjen describes that the datas are estimated using the leaf area index and leaf chlorophyll contend using the UA with the special case of the autotrophic bacteria.

The UAV is used for the data capturing,the data are simulated at the angular configurations and the datas are captured at different angles. The data values are correlated in terms of RMSE values.The front cameras of UAV is used for the data abstraction.

The spectral data are collected from the multi spectral camera. The FPI camera interferometer technology to capture the images.UAV is a ground based controller.

It gives a clear feature data extraction. It also gives precise and accurate data.

Daniel Gaviria-Palacio suggested a method to estimate the chlorophyll contend on plant leaves using the light sensors.In the paper "Fast estimation of chlorophyll content on plant 
leaves using the light sensor of a smartphone"[2],by Daniel Gaviria-Palacio,the leaf chlorophyll is estimated using smartphone light sensors.

The ambient light sensor value and the SPAD-502 TM value are compared for chlorophyll contend estimation.They obtain a good correlation.The light sensors are tested using the $3 \mathrm{D}$ printed device and a red LED.

The value of the light transmission are obtained using two adapters. The first adapter is used to locate the leaves and the other to position the plant leaf. The values of smartphone meter and the SPAD 502 are compared and the values estimate the chlorophyll contend.

The smartphones allows internet network for the data exchange among users. The chlorophyll measurements help to estimate nitrogen status in plants. The ambient light sensor measures the specific leaf light transmission and the chlorophyll estimation.

The light transmission values are scaled from 0 to 1 values.As the plant height increases, the transmission of the led decreases.

Pudong Liu suggest a method of integrating multiple vegetative indices for estimating leaf chlorophyll contend in the paper "Integrating multiple vegetation indices via an artificial neural network model for estimating the leaf chlorophyll content of Spartina alterniflora under interspecies competition"[3].Here we estimate the $\mathrm{Cab}$ contend by evaluating 79 published representative indices. Cab indicates chlorophyll $\mathrm{a}$ and $\mathrm{b}$.

Here the spectral relectance are measured using ASD field spec handheld Portable spectroradiometer and leaf clip.The classifier such as artificial neural network is used here.They are used to determine the leaf pigments and spectral indices and hence they are used to estimate the chlorophyll content .Out of 79 spectral indices, five spectral indices are selected. They are integrated using the ANN.

Artificial neural network

It is an interconnected group of nodes.They are used for image recognition. The connected nodes are called artificial neurons. It receives the signal. The connection transmit signal from one to another.

In the paper "Intelligent image analysis (IIA) using artificial neural network (ANN) for non-invasive estimation of chlorophyll content in micro propagated plants of potato"[4],S.Dutta gupta suggested the method of intelligent image analysis using artificial neural network.

The SPAD values are obtained and the rgb parameters are used.The measured chlorophyll value and the predicted chlorophyll value are compared in terms of RMSE value .

The RMSE value is calculated by the analyzing the predicted and measured chlorophyll content . The ANN model is more efficient than the linear rgb model.The ANN model uses non linear rgb model.

In the paper "Use of digital camera as alternative method for non-destructive detection of the leaf chlorophyll contend and the nitrogen nutrition status in wheat"[5] ,Jorg peter baresel suggests the use of a digital camera for the estimation purpose and the values are compared with the SPAD readings.

The SPAD value digital image analysis is used to estimate the nitrogen nutrient status. The massive chlorophyll contend and the biomass are good to indicate the nitrogen uptake.

The digital image analysis can directly determine the soil ground and thus it can estimate the biomass and the chlorophyll contend. The main aim is that it describes the suitable methods of image analysis. They are easy to implement and use. They estimate then chlorophyll content.

There are two basic procedures for image analysis. They are: Segmentation and colour analysis. Segmentation converts colour image to binary image.The R-G-B colours are distributed in separate layers. They are in values ranging from 0 to 255 .

The first step includes conversion of each pixel into unique index. The second step includes the separation of fractions.In the plant regions, the green colour dominates and the $G$ dominates over the $\mathrm{R}$ and $\mathrm{B}$.

In the paper" A correlation analysis on chlorophyll content and SPAD value in tomato leaves"[6], Chengyao jiang et al suggested a method to estimtate the chlorophyll contend by comparing with the SPAD value.

The chlorophyll a, chlorophyll $\mathrm{b}$ are calculated and then the values are compared with the SPAD value.

\section{CONCLUSION}

This paper is an attempt to consolidate different approaches for estimating chlorophyll content from the leaf images in visible spectrum. Such a research direction is promising in the way that traditional chlorophyll estimation method using SPAD meter is too expensive to the farmers to handle. If a reliable approach could be suggested, it would be of great benefit to the small and medium sized framers as they can measure the vigor of their plants simply using a smartphone. 
Table 1: Comparison of Works

\begin{tabular}{|c|c|c|c|c|}
\hline $\begin{array}{l}\text { Sl } \\
\text { No. }\end{array}$ & Publication & Methodology & Merits & Demerits \\
\hline 1 & $\begin{array}{l}\text { "Improved estimation of leaf area index } \\
\text { and leaf chlorophyll content of a } \\
\text { potato crop using multi-angle spectral } \\
\text { data - potential of unmanned } \\
\text { aerial vehicle imagery" by Peter } \\
\text { P.J.Roosjen et al.(2018)[1] }\end{array}$ & $\begin{array}{l}\text { Unmanned aerial } \\
\text { vehicle are used. LAI } \\
\text { and LCC features are } \\
\text { selected. Multi- angle } \\
\text { data are collected. }\end{array}$ & $\begin{array}{l}\text { Clear feature data } \\
\text { extraction } \\
\text { Give precise and } \\
\text { accurate data. }\end{array}$ & $\begin{array}{l}\text { High cost } \\
\text { Too dangerous for } \\
\text { humans. }\end{array}$ \\
\hline 2 & $\begin{array}{l}\text { "Fast estimation of chlorophyll content } \\
\text { on plant leaves using the light } \\
\text { sensor of a smartphone" Daniel Gaviria } \\
\text { Palacio et al.(2017)[2] }\end{array}$ & $\begin{array}{l}\text { Smartphone ambient } \\
\text { light sensor is used. }\end{array}$ & $\begin{array}{l}\text { Give more information } \\
\text { about color expense } \\
\text { To view wavelength of } \\
\text { light. }\end{array}$ & $\begin{array}{l}\text { Inaccurate } \\
\text { High response time. }\end{array}$ \\
\hline 3 & $\begin{array}{l}\text { "Integrating multiple vegetation indices } \\
\text { via an artificial neural network } \\
\text { model for estimating the leaf chlorophyll } \\
\text { content of Spartina alterniflora under } \\
\text { interspecies competition" Pudong Liu \& } \\
\text { Runhe Shi et al.(2017)[3] }\end{array}$ & $\begin{array}{l}\text { Artificial Neural } \\
\text { Network model } \\
\text { Spectral indices are } \\
\text { selected. }\end{array}$ & $\begin{array}{l}\text { Trained model } \\
\text { Self-adaptive. }\end{array}$ & $\begin{array}{l}\text { Need long training } \\
\text { time } \\
\text { Need lots of data } \\
\text { More complicated. }\end{array}$ \\
\hline 4 & $\begin{array}{l}\text { "Intelligent image analysis (IIA) using } \\
\text { artificial neural network (ANN) for non- } \\
\text { invasive estimation of chlorophyll } \\
\text { content in micropropagated plants of } \\
\text { potato", S. Dutta Gupta et.al.(2017)[4] }\end{array}$ & $\begin{array}{l}\text { Artificial Neural } \\
\text { Network Model. }\end{array}$ & Flexible. & $\begin{array}{l}\text { Needs lot of data. } \\
\text { Computationally } \\
\text { intensive. }\end{array}$ \\
\hline 5 & $\begin{array}{l}\text { "Use of digital camera as alternative } \\
\text { method for non-destructive detection of } \\
\text { the leaf chlorophyll content and the } \\
\text { nitrogen nutrition } \\
\text { status in wheat", Jorg peter Baresel et } \\
\text { al.(2017)[5 }\end{array}$ & $\begin{array}{l}\text { Digital cameras based } \\
\text { capturing. }\end{array}$ & & $\begin{array}{l}\text { Time and Energy } \\
\text { consuming. } \\
\text { High cost. }\end{array}$ \\
\hline
\end{tabular}

\section{REFERENCES}

[1] Peter P.J. Roosjena,, Benjamin Bred et al. Improved estimation of leaf area index and leaf chlorophyll content of a potato crop using multi-angle spectral data - potential of unmanned aerial vehicle imagery Int $\mathbf{J}$ Appl Earth Obs Geoinformation 66 (2018) 14-2

[2] Daniel Gaviria Palacio et al. Fast estimation of chlorophyll content on plant leaves using the light sensor of a smartphone (2017)

[3] Pudong Liu \& Runhe Shi et al. Integrating multiple vegetation indices via an artificial neural network model for estimating the leaf chlorophyll content of Spartina alterniflora under interspecies competition (2017) Environ Monit Assess (2017) 189:596
[4] S. Dutta Gupta1 \& A. K. Pattanayak et al. Intelligent image analysis (IIA) using artificial neural network (ANN) for non-invasive estimation of chlorophyll content in micropropagated plants of potato (2017) Springer publications

[5] Jorg peter Baresel et al. Use of digital camera as alternative method for non-destructive detection of the leaf chlorophyll content and the nitrogen nutrition status in wheat (2017) Computers and Electronics in Agriculture

[6] Chengyao Jiang et al. A correlation analysis on chlorophyll content and SPAD value in tomato leaves (2017) Hort Research No. 71 